\title{
Facile isomerization of silyl enol ethers catalyzed by triflic imide and its application to one-pot isomerization- $(2+2)$ cycloaddition
}

\author{
Kazato Inanaga ${ }^{1}$, Yu Ogawa², Yuuki Nagamoto², Akihiro Daigaku", \\ Hidetoshi Tokuyama ${ }^{1}$, Yoshiji Takemoto ${ }^{2}$ and Kiyosei Takasu* ${ }^{* 2}$
}

\section{Letter}

Address:

${ }^{1}$ Graduate School of Pharmaceutical Sciences, Tohoku University, Aobayama, Sendai 980-8578, Japan and ${ }^{2}$ Graduate School of Pharmaceutical Sciences, Kyoto University, Yoshida, Sakyo, Kyoto 606-8501, Japan

Email:

Kiyosei Takasu* - kay-t@pharm.kyoto-u.ac.jp

* Corresponding author

Keywords:

isomerization; one-pot reaction; organocatalysis; silyl enol ethers; triflic imide

\author{
Beilstein J. Org. Chem. 2012, 8, 658-661. \\ doi:10.3762/bjoc.8.73 \\ Received: 29 February 2012 \\ Accepted: 05 April 2012 \\ Published: 27 April 2012 \\ This article is part of the Thematic Series "Organocatalysis". \\ Guest Editor: B. List \\ (c) 2012 Inanaga et al; licensee Beilstein-Institut. \\ License and terms: see end of document.
}

\begin{abstract}
A triflic imide $\left(\mathrm{Tf}_{2} \mathrm{NH}\right)$ catalyzed isomerization of kinetically favourable silyl enol ethers into thermodynamically stable ones was developed. We also demonstrated a one-pot catalytic reaction consisting of $(2+2)$ cycloaddition and isomerization. In the reaction sequence, $\mathrm{Tf}_{2} \mathrm{NH}$ catalyzes both of the reactions.
\end{abstract}

\section{Introduction}

Silyl enol ethers, which are isolable equivalents of metal enolates, are useful and important intermediates in synthetic chemistry [1-3]. They react as a good nucleophile for the introduction of a carbon skeleton or a functional group at the $\alpha$-position of a carbonyl group under appropriate conditions. Although silyl enol ethers are easily prepared from the corresponding ketones, the regiochemical issue would arise in the case of asymmetric ketones. Treatment with a strong base such as lithium diisopropylamide (LDA), followed by silyl chloride, under cryogenic conditions selectively affords kinetically favourable silyl enol ethers. On the other hand, thermodynami- cally stable ones can be predominantly obtained by the reaction with a silylating agent in the presence of a weak base, such as triethylamine, under equilibration conditions. Although the preparation of silyl enol ethers has been extensively studied, there have only been a limited number of studies on their isomerization [4-7]. Deyine reported that a catalytic amount of triethylammonium chloride promotes the isomerization to give thermodynamically favourable ones in moderate yield [5]. However, harsh conditions (reaction temperature: ca. 100 to $200{ }^{\circ} \mathrm{C}$ ) were required for the complete equilibration. Yamamoto and co-workers reported that a $\mathrm{SnCl}_{4}-(\mathrm{BINOL}$ 
monomethyl ether) complex (5-10 mol \%) catalyzes the isomerization of silyl enol ethers at $-78{ }^{\circ} \mathrm{C}$ [6]. By using this catalyst, they remarkably achieved the kinetic resolution of racemic silyl enol ethers. To make this isomerization synthetically useful and valuable, the development of more-reactive catalysts and a facile procedure would be required. In this communication, we describe isomerization of silyl enol ethers by an organocatalyst under mild conditions and its application to a one-pot catalytic reaction involving isomerization of silyl enol ethers and $(2+2)$ cycloaddition.

\section{Results and Discussion}

During our research on triflic imide $\left(\mathrm{Tf}_{2} \mathrm{NH}\right)$-catalyzed reactions [8], we accidentally found that the isomerization of kinetically favourable silyl enol ethers into thermodynamically stable ones occurs smoothly in the presence of $\mathrm{Tf}_{2} \mathrm{NH}$. When the TBS enol ether $1 \mathrm{a}$ was treated with a catalytic amount of $\mathrm{Tf}_{2} \mathrm{NH}$ $(1.0 \mathrm{~mol} \%)$ in $\mathrm{CH}_{2} \mathrm{Cl}_{2}$ at ambient temperature, isomerization resulted in the thermodynamically stable $\mathbf{2 a}$ in $92 \%$ yield along with the recovered 1a and ketone $\mathbf{3}$ (Table 1, entry 1). Equilibrium was reached within $5 \mathrm{~min}$. The reaction using $20 \mathrm{~mol} \%$ of $\mathrm{Tf}_{2} \mathrm{NH}$ resulted in an increase of decomposition into 3 (entry 2). When the reaction was performed at $-10{ }^{\circ} \mathrm{C}$, the chemical yield of 2 was slightly improved (entry 3 ). In contrast, no isomerization was observed at $-78{ }^{\circ} \mathrm{C}$ even after $1 \mathrm{~h}$ (entry 4 ). The catalytic isomerization reaction also proceeded in toluene (entry 5), but no (or almost no) isomerization occurred in $\mathrm{CH}_{3} \mathrm{CN}$ (entry 6). When 10-camphorsulfonic acid (5 mol \%) was used as a catalyst for $1 \mathrm{~h}$, the isomerization was incomplete (entry 7). Enol ethers bearing typical silyl groups were also isomerized (entries 8-12). The decomposition of TMS enol ether $\mathbf{1 b}$ into 3b slightly increased at ambient temperature compared to that at $-10{ }^{\circ} \mathrm{C}$ (entries 8 and 9). In the reaction of TIPS enol ether 1d, the reaction rate decreased and more catalyst ( $5 \mathrm{~mol} \%$ ) was necessary to achieve equilibrium within 5 min (entry 12).

Several silyl enol ethers were explored for catalytic isomerization under the optimized conditions ( $1 \mathrm{~mol} \%$ of $\mathrm{Tf}_{2} \mathrm{NH}$, $-10{ }^{\circ} \mathrm{C}, \mathrm{CH}_{2} \mathrm{Cl}_{2}$ ). The results are summarized in Table 2. All the kinetically favourable silyl enol ethers 1 were smoothly isomerized to the thermodynamically stable $\mathbf{2}$ in the presence of $\mathrm{Tf}_{2} \mathrm{NH}$.

A plausible mechanism for the catalytic isomerization is shown in Scheme 1. Silyl enol ether $\mathbf{1}$ is rapidly protonated by a catalytic amount of $\mathrm{Tf}_{2} \mathrm{NH}$ to give the corresponding siloxonium cation $\mathbf{4}$, and, then, another molecule of silyl enol ether $\mathbf{1}$ deprotonates the $\alpha$-position of 4 . Equilibration results in the selective production of the thermodynamically more stable 2 . As a side reaction, the counter anion, $\mathrm{Tf}_{2} \mathrm{~N}^{-}$, could attack the silicon atom of 2 to produce silyl triflic imide $\left(\mathrm{R}_{3} \mathrm{SiNTf}_{2}\right)$ [8-12] and the corresponding ketone 3 . Therefore, the use of a large amount of $\mathrm{Tf}_{2} \mathrm{NH}$ causes decomposition into 3 (Table 1, entry 2).

Table 1: $\mathrm{Tf}_{2} \mathrm{NH}$-catalyzed isomerization of silyl enol ethers. ${ }^{\mathrm{a}, \mathrm{b}}$<smiles>CC1CC=C(O[GaH])C(C)C1</smiles>

1

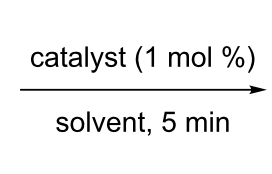

solvent<smiles>[R3]OC1=C(C)CCCC1</smiles>

2

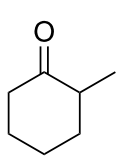

3

\begin{tabular}{|c|c|c|c|c|c|c|}
\hline \multirow[t]{2}{*}{ entry } & \multirow[t]{2}{*}{$1\left(\mathrm{SiR}_{3}\right)$} & \multirow[t]{2}{*}{ solvent } & \multirow[t]{2}{*}{ temp. $\left({ }^{\circ} \mathrm{C}\right)$} & \multicolumn{3}{|c|}{$\%$ yield } \\
\hline & & & & 2 & 1 (recovd.) & 3 \\
\hline 1 & $1 \mathrm{a}(\mathrm{TBS})$ & $\mathrm{CH}_{2} \mathrm{Cl}_{2}$ & $\mathrm{rt}$ & 92 & 6 & 2 \\
\hline $2^{c}$ & $1 \mathrm{a}$ & $\mathrm{CH}_{2} \mathrm{Cl}_{2}$ & $\mathrm{rt}$ & 71 & 4 & 25 \\
\hline 3 & $1 a$ & $\mathrm{CH}_{2} \mathrm{Cl}_{2}$ & -10 & 93 & 4 & 3 \\
\hline $4^{d}$ & $1 \mathrm{a}$ & $\mathrm{CH}_{2} \mathrm{Cl}_{2}$ & -78 & 1 & 97 & 2 \\
\hline 5 & $1 a$ & toluene & -10 & 92 & 5 & 2 \\
\hline 6 & $1 a$ & $\mathrm{CH}_{3} \mathrm{CN}$ & -10 & 2 & 96 & 2 \\
\hline $7^{d, e, f}$ & $1 \mathrm{a}$ & $\mathrm{CH}_{2} \mathrm{Cl}_{2}$ & -10 & 25 & 64 & 11 \\
\hline 8 & 1b (TMS) & $\mathrm{CH}_{2} \mathrm{Cl}_{2}$ & $\mathrm{rt}$ & 85 & 6 & 9 \\
\hline 9 & $1 b$ & $\mathrm{CH}_{2} \mathrm{Cl}_{2}$ & -10 & 91 & 4 & 5 \\
\hline 10 & $1 b$ & $\mathrm{CH}_{2} \mathrm{Cl}_{2}$ & -78 & 0 & 95 & 5 \\
\hline 11 & 1c (TES) & $\mathrm{CH}_{2} \mathrm{Cl}_{2}$ & -10 & 78 & 5 & 17 \\
\hline $12^{\mathrm{e}}$ & 1d (TIPS) & $\mathrm{CH}_{2} \mathrm{Cl}_{2}$ & -10 & 92 & 3 & 5 \\
\hline
\end{tabular}

aYields were determined by GC-MS. ${ }^{b}$ Regioisomer 1 (>99\% purity) was used as a substrate. ${ }^{c} 20$ mol $\%$ of catalyst was used. ${ }^{d}$ Reactions were carried out for $1 \mathrm{~h}$. ${ }^{\mathrm{e}} 5 \mathrm{~mol} \%$ of catalyst was used. ${ }^{\mathrm{f}} 10$-Camphorsulfonic acid was used as a catalyst. 


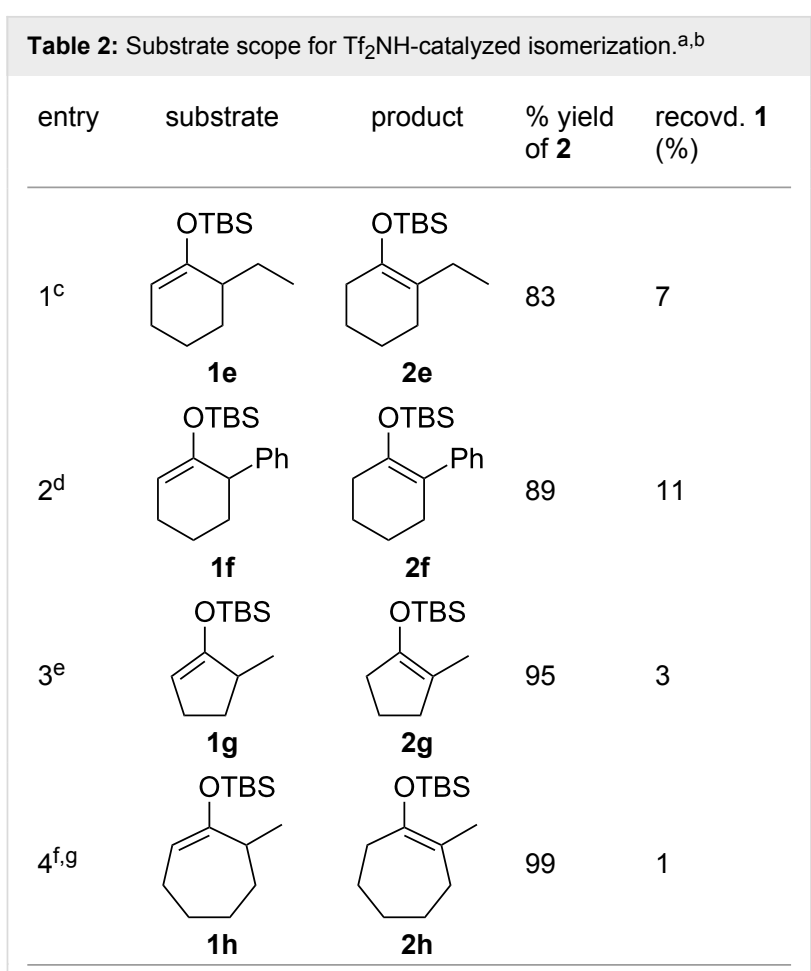

aReactions were performed under the same conditions as given in Table 1 , entry 3 . bYields were determined by GC-MS. 'Purity of $1 \mathrm{e}$ is $99 \%$ (including isomer $\mathbf{2 e}(1 \%)$ ). dPurity of $\mathbf{1 f}$ is $100 \%$ (no isomer $\mathbf{2} \mathbf{f}$ ). epurity of $\mathbf{1 g}$ is $95 \%$ (including isomer $\mathbf{2 g}(5 \%)$ ). ${ }^{\mathrm{f}} \mathrm{Purity}$ of $\mathbf{1 h}$ is $93 \%$ (including isomer $2 \mathrm{~h}(7 \%)$ ). ${ }^{9} 5 \mathrm{~mol} \%$ of $\mathrm{Tf}_{2} \mathrm{NH}$ was used.

We have previously reported the $\mathrm{Tf}_{2} \mathrm{NH}$ catalyzed $(2+2)$ cycloaddition of silyl enol ethers with acrylates generating substituted cyclobutanes [10]. We are intrigued that the isomerization of silyl enol ethers and successive $(2+2)$ cycloaddition could be promoted by $\mathrm{Tf}_{2} \mathrm{NH}$ in a one-pot reaction. When $\mathbf{1 a}$ was treated with $\mathrm{Tf}_{2} \mathrm{NH}(1 \mathrm{~mol} \%)$ under the isomerization conditions $\left(-10^{\circ} \mathrm{C}\right)$, followed by the addition of methyl acrylate (5) at $-78{ }^{\circ} \mathrm{C}$, 6-methylbicyclo[4.2.0]octane 6 and its diastereomer were obtained in $86 \%$ and $6 \%$, respectively

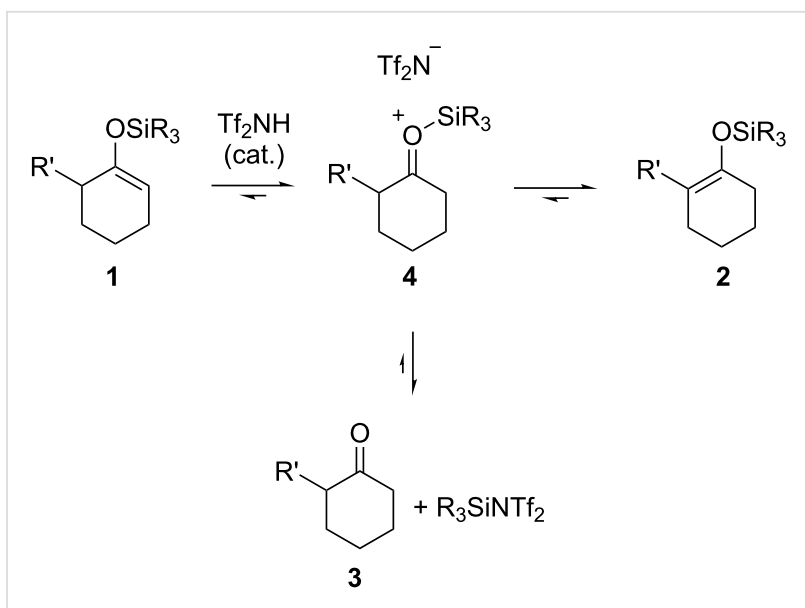

Scheme 1: Plausible mechanism for $\mathrm{Tf}_{2} \mathrm{NH}$-catalyzed isomerization of silyl enol ethers.

(Scheme 2a). No formation of their regioisomers was observed. The obtained compound $\mathbf{6}$ is identical to the product in the reaction of $\mathbf{2 a}$ with $\mathbf{5}[10,13]$. It is noteworthy that two different reactions, isomerization and $(2+2)$ cycloaddition, are catalyzed by $\mathrm{Tf}_{2} \mathrm{NH}$ [14-18]. By contrast, when $\mathbf{1 a}$ reacted with $\mathbf{5}$ in the presence of $\mathrm{Tf}_{2} \mathrm{NH}$ at $-78{ }^{\circ} \mathrm{C},(2+2)$ cycloaddition directly proceeded to give 2-methylbicyclo[4.2.0] octane 7 in 66\% yield along with the formation of two diastereomers (Scheme $2 b$ ). Obviously, at this temperature, no isomerization of 1 a occurred.

The above finding can be applied to $(2+2)$ cycloaddition, even if a mixture of regioisomeric silyl enol ethers is used as a substrate (Scheme 3 ). Thus, the reaction of ketone $\mathbf{3 h}$ with TBSOTf in the presence of $\mathrm{NEt}_{3}$ afforded a regioisomeric mixture of silyl enol ethers $\mathbf{1 h}$ and $\mathbf{2 h}$ (ca. 7:3). After extraction to remove the amine reagent, the crude regioisomeric mixture was subjected to $\mathrm{Tf}_{2} \mathrm{NH}$ at $-10{ }^{\circ} \mathrm{C}$ and subsequently reacted with acrylate 5 to afford $(2+2)$ cycloadduct $\mathbf{8}$ in $70 \%$ yield. This result indicates that the $\mathrm{Tf}_{2} \mathrm{NH}$ catalyzed reaction can save not

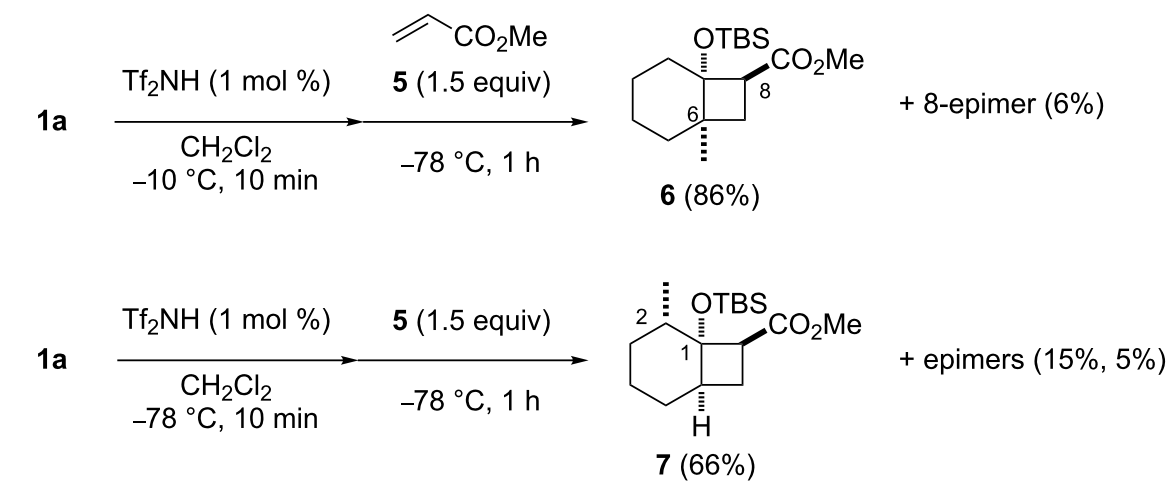

(a)

(b) 


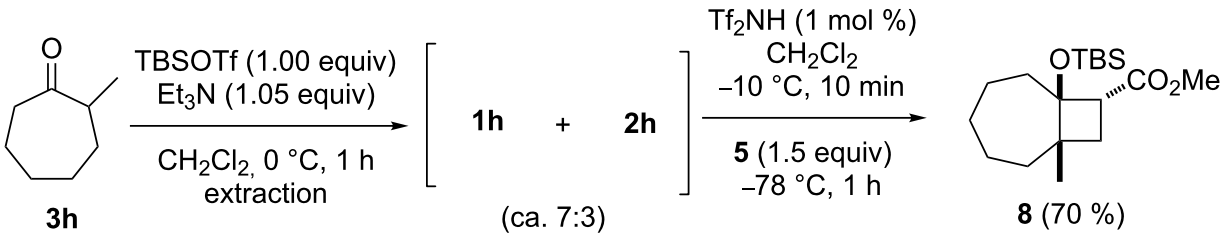

Scheme 3: Formation of bicyclo[5.2.0]octane from the regioisomeric mixture of silyl enol ethers.

only the separation to remove the corresponding kinetically favourable regioisomer, but also loss of the undesired regioisomer.

\section{Conclusion}

In summary, we have developed a new catalytic isomerization reaction of silyl enol ethers. Kinetically favourable silyl enol ethers were smoothly converted into thermodynamically stable ones by treatment with a catalytic amount of $\mathrm{Tf}_{2} \mathrm{NH}$ under mild conditions. Moreover, we demonstrated that the one-pot reaction involves two different catalytic reactions, an isomerization and a $(2+2)$ cycloaddition.

\section{Supporting Information}

\section{Supporting Information File 1}

Experimental details and spectral data.

[http://www.beilstein-journals.org/bjoc/content/ supplementary/1860-5397-8-73-S1.pdf]

\section{Acknowledgements}

This work was supported by Grants-in-Aid for Scientific Research on Innovative Areas "Reaction Integration" (2105) from the Ministry of Education, Culture, Sports, Science and Technology, Japan and the Naito Foundation.

\section{References}

1. Brownbridge, P. Synthesis 1983, 1-28. doi:10.1055/s-1983-30204

2. Brownbridge, P. Synthesis 1983, 85-104. doi:10.1055/s-1983-30234

3. Poirier, J.-M. Org. Prep. Proced. Int. 1988, 20, 317-369. doi:10.1080/00304948809355878

4. Stork, G.; Hudrlik, P. F. J. Am. Chem. Soc. 1968, 90, 4462-4464. doi:10.1021/ja01018a051

5. Deyine, A.; Dujardin, G.; Mammeri, M.; Poirier, J.-M. Synth. Commun. 1998, 28, 1817-1821. doi:10.1080/00397919808007012

6. Ishihara, K.; Nakamura, H.; Nakamura, S.; Yamamoto, H. J. Org. Chem. 1998, 63, 6444-6445. doi:10.1021/jo9812936

7. Aikawa, H.; Kaneko, T.; Asao, N.; Yamamoto, Y. Beilstein J. Org. Chem. 2011, 7, 648-652. doi:10.3762/bjoc.7.76

8. Takasu, K. Synlett 2009, 1905-1914. doi:10.1055/s-0029-1217522

9. Ishihara, K.; Hiraiwa, Y.; Yamamoto, H. Synlett 2001, 1851-1854. doi:10.1055/s-2001-18761
10. Inanaga, K.; Takasu, K.; Ihara, M. J. Am. Chem. Soc. 2005, 127, 3668-3669. doi:10.1021/ja042661s

11. Boxer, M. B.; Yamamoto, H. J. Am. Chem. Soc. 2006, 128, 48-49. doi:10.1021/ja054725k

12. Takasu, K.; Miyakawa, Y.; Ihara, M.; Tokuyama, H. Chem. Pharm. Bull. 2008, 56, 1205-1206. doi:10.1248/cpb.56.1205

13. Kurahashi, K.; Takemoto, Y.; Takasu, K. ChemSusChem 2012, 5, 270-273. doi:10.1002/cssc.201100373

14. Fogg, D. E.; dos Santos, E. N. Coord. Chem. Rev. 2004, 248, 2365-2379. doi:10.1016/j.ccr.2004.05.012

15. Shindoh, N.; Takemoto, Y.; Takasu, K. Chem.-Eur. J. 2009, 15, 12168-12179. doi:10.1002/chem.200901486

16. Shindoh, N.; Tokuyama, H.; Takemoto, Y.; Takasu, K. J. Org. Chem. 2008, 73, 7451-7456. doi:10.1021/jo8009243

17. Takasu, K.; Tanaka, T.; Azuma, T.; Takemoto, Y. Chem. Commun. 2010, 46, 8246-8248. doi:10.1039/c0cc03336g

18. Azuma, T.; Takemoto, Y.; Takasu, K. Chem. Pharm. Bull. 2011, 59, 1190-1193. doi:10.1248/cpb.59.1190

\section{License and Terms}

This is an Open Access article under the terms of the Creative Commons Attribution License (http://creativecommons.org/licenses/by/2.0), which permits unrestricted use, distribution, and reproduction in any medium, provided the original work is properly cited.

The license is subject to the Beilstein Journal of Organic Chemistry terms and conditions:

(http://www.beilstein-journals.org/bjoc)

The definitive version of this article is the electronic one which can be found at: doi:10.3762/bjoc. 8.73 